\title{
Lumbar microdiscectomy complication rates: a systematic review and meta-analysis
}

\author{
Michael F. Shriver, BS, ${ }^{1}$ Jack J. Xie, MS, ${ }^{2}$ Erik Y. Tye, BA, ${ }^{1}$ Benjamin P. Rosenbaum, MD, ${ }^{3,4}$ \\ Varun R. Kshettry, MD, ${ }^{3,4}$ Edward C. Benzel, MD, ${ }^{3,4}$ and Thomas E. Mroz, MD ${ }^{4,5}$ \\ ${ }^{1}$ School of Medicine and ${ }^{2}$ Department of Physiology and Biophysics, Case Western Reserve University; ${ }^{3}$ Department of \\ Neurosurgery, ${ }^{4}$ Center for Spine Health, and ${ }^{5}$ Department of Orthopaedic Surgery, Cleveland Clinic, Cleveland, Ohio
}

OBJECT Lumbar microdiscectomy and its various minimally invasive surgical techniques are seeing increasing popularity, but a systematic review of their associated complications has yet to be performed. The authors sought to identify all prospective clinical studies reporting complications associated with lumbar open microdiscectomy, microendoscopic discectomy (MED), and percutaneous microdiscectomy.

METHODS The authors conducted MEDLINE, Scopus, Web of Science, and Embase database searches for randomized controlled trials and prospective cohort studies reporting complications associated with open, microendoscopic, or percutaneous lumbar microdiscectomy. Studies with fewer than 10 patients and published before 1990 were excluded. Overall and interstudy median complication rates were calculated for each surgical technique. The authors also performed a meta-analysis of the reported complications to assess statistical significance across the various surgical techniques.

RESULTS Of 9504 articles retrieved from the databases, 42 met inclusion criteria. Most studies screened were retrospective case series, limiting the number of studies that could be included. A total of 9 complication types were identified in the included studies, and these were analyzed across each of the surgical techniques. The rates of any complication across the included studies were $12.5 \%, 13.3 \%$, and $10.8 \%$ for open, MED, and percutaneous microdiscectomy, respectively. New or worsening neurological deficit arose in $1.3 \%, 3.0 \%$, and $1.6 \%$ of patients, while direct nerve root injury occurred at rates of $2.6 \%, 0.9 \%$, and $1.1 \%$, respectively. Hematoma was reported at rates of $0.5 \%, 1.2 \%$, and $0.6 \%$, respectively. Wound complications (infection, dehiscence, or seroma) occurred at rates of $2.1 \%$, $1.2 \%$, and $0.5 \%$, respectively. The rates of recurrent disc complications were $4.4 \%, 3.1 \%$, and $3.9 \%$, while reoperation was indicated in $7.1 \%$, $3.7 \%$, and $10.2 \%$ of operations, respectively. Meta-analysis calculations revealed a statistically significant higher rate of intraoperative nerve root injury following percutaneous procedures relative to MED. No other significant differences were found.

CONCLUSIONS This review highlights complication rates among various microdiscectomy techniques, which likely reflect real-world practice and conceptualization of complications among physicians. This investigation sets the framework for further discussions regarding microdiscectomy options and their associated complications during the informed consent process.

http://thejns.org/doi/abs/10.3171/2015.7.FOCUS15281

KEY WORDS lumbar microdiscectomy; microendoscopic discectomy; percutaneous discectomy; complications; systematic review; meta-analysis

ABBREVIATIONS IQR = interquartile range; MED = microendoscopic discectomy; MIS = minimally invasive surgical; PCS = prospective cohort study; PRISMA = Preferred Reporting Items for Systematic Reviews and Meta-Analyses; RCT = randomized controlled trial.

SUBMITTED May 31, 2015. ACCEPTED July 22, 2015.

INCLUDE WHEN CITING DOI: 10.3171/2015.7.FOCUS15281. 
$\mathrm{W}$ HILE the traditional open microdiscectomy technique provides excellent outcomes, it carries the risk of complications such as postoperative CSF leak, nerve root injury, and postoperative pain. ${ }^{24,55,63,64} \mathrm{Be}$ cause minimally invasive surgical (MIS) techniques, such as microendoscopic discectomy (MED) and percutaneous microdiscectomy, minimize the manipulation of surrounding tissue, they have been purported to decrease complication rates and reduce postoperative pain in addition to improving function. ${ }^{15,20}$ However, outcome studies have yet to verify the claims that MIS techniques for lumbar microdiscectomy are better than conventional methods. ${ }^{34}$

Complications related to lumbar microdiscectomy are typically analyzed from an institutional or individual surgeon perspective., ${ }^{4,53}$ A systematic review and metaanalysis of complications following the various surgical techniques to perform lumbar microdiscectomy has not been previously performed. Accurate knowledge of complication rates following conventional open, MED, and percutaneous approaches can be used to help educate patients and surgeons during the informed consent process. We sought to identify differences in complication rates among open, MED, and percutaneous microdiscectomy by performing a systematic review and meta-analysis of all complications reported in clinical studies.

\section{Methods \\ Study Search}

The systematic review was conducted following Preferred Reporting Items for Systematic Reviews and MetaAnalyses (PRISMA). ${ }^{39}$ We conducted MEDLINE, Scopus, Web of Science, and Embase database searches with the search algorithm: ("Lumbar Discectomy Complication(s)") OR ("Lumbar Discectomy Complication(s) and Outcome(s)") OR (("Lumbar" and "Discectomy" or "Microdiscectomy") AND ("Complications" or "Outcomes")). The search returned 9504 citations. We searched for articles published between January 1, 1990, and December 27, 2014.

\section{Inclusion and Exclusion Criteria}

Articles published prior to 1990 were excluded to avoid a historical bias and because MIS techniques were not yet widely used. ${ }^{59}$ To create a more homogenous patient cohort, studies involving the following procedures were excluded: interbody fusion, transperitoneal lumbar microdiscectomy, corpectomy, revision surgery, and lumbar microdiscectomy spanning more than one vertebral level. We included studies in which lumbar microdiscectomy was performed for degenerative indications and excluded those in which lumbar discectomy was performed to treat infection and tumor pathological processes. We imposed no restrictions on publication status. Animal, in vitro, biomechanical, and non-English language studies were excluded. We also excluded those concerning large administrative data sets because different surgical techniques were not separated and many complications are frequently underreported in coded data. We included prospective cohort studies (PCSs) and randomized controlled trials (RCTs; experimental or control arms). We excluded all retrospective chart reviews since many complications are underreported in retrospective studies. For clinical studies using duplicate data, only the study with the most recent results was included.

\section{Data Collection}

Three reviewers (M.F.S., J.J.X., and E.Y.T.) independently conducted data extraction from the 42 included articles. The extracted data sets were compared to confirm accuracy. Level of evidence for each of the included articles was assessed using the Oxford Centre for Evidence Based Medicine Level of Evidence 2 classification system (http:// www.cebm.net/ocebm-levels-of-evidence/). From the eligible articles, we recorded the publication year, follow-up period (months), number of patients, complications, and collection method. The included studies reported the following complications: nerve root injury, new or worsening neurological deficit, medical complications, surgical errors, durotomy, hematoma, wound complications, recurrent disc complications at the primary surgical site, and reoperation. Criteria and definitions for each complication are summarized in Table 1. Nerve root injuries were recorded separately from new or worsening neurological deficit because some studies reported intraoperative puncture, displacement, or direct injury to the nerve root but did not correlate it to postoperative neurological deficit development. Additionally, surgical errors consisted of exploration started at the wrong vertebral level and surgical instrument breakage during the operative procedure.

Open lumbar microdiscectomy surgeries use a longitudinal midline incision over the area of the herniated disc

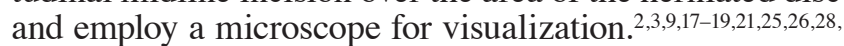
33,36,41-43,45,49,52-54,56-58,61 MED techniques employ a longitudinal paramedian incision through which a tubular retractor is placed and visualization is achieved through an endoscope. $2,6,10,13,19,24,25,29,36,46,51,53,57,60,62,64$ Percutaneous discectomy entails placing a sheath directly into the disc space via a transforaminal approach, extraforaminal approach, or interlaminar approach and then using a suction/debrider or chemical injection to remove the disc. ${ }^{1,11,12,23,30,37,44,50}$

To assess the risk of bias for each study, 3 reviewers (M.F.S., J.J.X., and E.Y.T.) independently investigated the individual studies and used The Cochrane Collaboration's tool for assessing risk of bias. ${ }^{22}$ Bias risk assessment was performed at the study level. Inconsistencies in bias risk assessment were reconciled through discussion.

\section{Statistical Analysis}

Unweighted overall mean complication rates were calculated by the summation of total complication events divided by the overall number of patients included in the studies reporting that specific complication. If a study reported zero events for a particular complication, the study's cohort was included in the denominator. To assess the variation in the rate of a specific complication across studies, an interstudy median and interquartile range (IQR), which ranged from the first to the third quartile (Q1-Q3), were calculated to demonstrate variations in specific cross-study complication rates.

We also analyzed complication data using a random- 
TABLE 1. Criteria and definitions for complications reported among included studies

\begin{tabular}{ll}
\hline \multicolumn{1}{c}{ Complication } & Criteria \\
\hline Nerve root injury* & $\begin{array}{c}\text { Defined as any intraop nerve root puncture or direct nerve root injury \& nerve root dis- } \\
\text { placement }\end{array}$ \\
\hline New or worsening neurological deficit & $\begin{array}{l}\text { Included increased motor or sensory deficit or new postop radiculopathy } \\
\text { Included deep vein thrombosis, pulmonary embolism, myocardial infarction, urinary tract } \\
\text { infection, acute kidney or lung disorders, \& respiratory distress or failure }\end{array}$ \\
\hline Medical complications & $\begin{array}{c}\text { Consisted of exploration started at wrong vertebral level \& surgical instrument breakage } \\
\text { during the procedure }\end{array}$ \\
\hline Surgical errors & Recorded for any incidental intraop injury to dura or postop CSF leak \\
\hline Hematoma & Included wound \& perineural hematoma \\
\hline Wound complications & $\begin{array}{c}\text { Included cellulitis, discitis, spondylodiscitis, skin infection, superficial wound infection, } \\
\text { suture granuloma, dehiscence, \& seroma }\end{array}$ \\
\hline Recurrent disc complications & Included any persistent or relapsing disc herniation or prolapse \\
\hline Reoperation & Included any reop during the postop period, regardless of indication \\
\hline * Studies reporting intraoperative nerve root injury without subsequent correlation to postoperative neurological deficit.
\end{tabular}

effects model with inverse variance weighting. Calculations for the meta-analysis and construction of forest plots were completed using an established spreadsheet by Neyeloff et al ${ }^{40}$ The principal summary measures were the effect summary values and $95 \%$ CIs. The presence of zero complication events in some studies did not permit calculations. To allow for inclusion of these studies, we substituted a value of 0.1 complication events per study and calculations were performed using this value. Because of the lack of consistent control groups across all included studies, we were unable to calculate relative risk ratios. We compared results among studies with $95 \%$ CIs and forest plots.

To assess heterogeneity between individual studies, a Q statistic and $\mathrm{I}^{2}$ value were calculated within each complication's meta-analysis. Delong et al. ${ }^{14}$ established an $\mathrm{I}^{2}$ less than $25 \%$ as low heterogeneity, $25 \%-75 \%$ as moderate heterogeneity, and greater than $75 \%$ as severe heterogeneity. These same values were used to assess heterogeneity in our meta-analysis.

\section{Results \\ Study Selection}

After removing 6870 duplicates, the titles and abstracts of 2634 publications were screened (Figs. 1 and 2, Table 2). ${ }^{39}$ The full text was assessed in the resulting 402 articles for eligibility criteria. Full-text assessment resulted in 42 eligible articles $(0.4 \%)$ to be included in the final analysis. Twenty-four studies reported utilization of the open microdiscectomy technique, while 16 and 8 studies reported the use of MED and percutaneous approaches, respectively.

Bias risk assessment of the included studies identified a marked difference between RCTs and PCSs, with RCTs demonstrating significantly less bias among sequence generation, allocation concealment, and blinding of participants, personnel, and outcome assessors (Table 3). ${ }^{22}$ No studies demonstrated a high risk of incomplete outcome data or selective reporting of outcomes. ${ }^{22}$

\section{Neurological Injuries}

Intraoperative nerve root injury was identified by 19 studies (Table 4, Figs. 3 and 4). Studies performing open, MED, and percutaneous techniques resulted in unweighted means of $2.6 \%$ (median $0.0 \%$ ), $0.9 \%$ (median $0.7 \%$ ), and $1.1 \%$ (median $0.7 \%$ ), respectively. Meta-analysis calculations revealed a statistically significant higher rate of intraoperative nerve root injury following percutaneous procedures relative to MED. A new or worsening neurological deficit was reported in 15 studies. Studies involving open microdiscectomy, MED, and percutaneous microdiscectomy resulted in unweighted means of $1.3 \%$ (median 1.2\%), 3.0\% (median 2.8\%), and 1.6\% (median $5.0 \%$ ), respectively. Meta-analysis calculations indicated no statistically significant difference between the surgical techniques.

\section{General Complications}

Medical complications were reported in 10 studies but not in any studies performing percutaneous microdiscectomy (Table 4, Figs. 3 and 4). Open microdiscectomy and MED resulted in rates of medical complications of $2.6 \%$ (median 2.6\%) and 2.6\% (median $0.0 \%$ ), respectively. Surgical errors were reported only in studies that involved open microdiscectomy and MED at rates of $3.1 \%$ (median $3.1 \%$ ) and $1.0 \%$ (median 1.0\%), respectively. No statistically significant differences were found among the different approaches.

\section{Durotomy-Related Complications}

Durotomy was identified in 29 studies (Table 4, Figs. 3 and 4). Open and MED techniques resulted in unweighted means of $3.9 \%$ (median $4.9 \%$ ) and $4.5 \%$ (median 4.8\%), respectively. Postoperative CSF leakage was reported by 1 study for open (1.3\%) and MED (0.6\%) approaches. ${ }^{2}$ Meta-analysis calculations, of durotomy rates, indicated no statistically significant difference among the surgical techniques. 


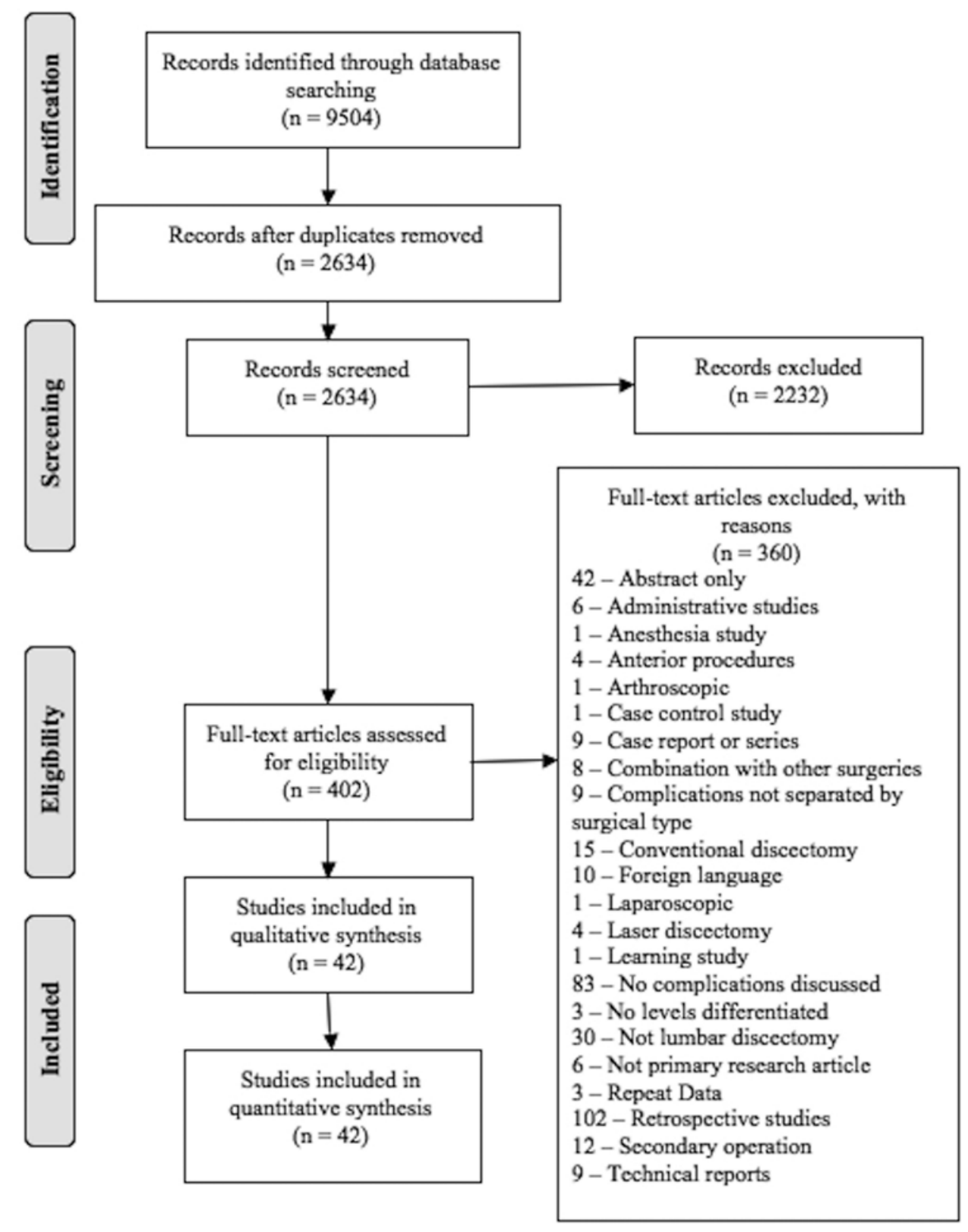

FIG. 1. PRISMA flow diagram.

\section{Wound Complications}

Nine total studies reported the development of a wound hematoma (Table 4, Figs. 3 and 4). Open, MED, and percutaneous microdiscectomy studies reported rates of $0.5 \%$ (median 0.6\%), 1.2\% (median 1.2\%), and 0.6\% (median $0.8 \%$ ), respectively. Wound complications were identified in 33 studies. Open, MED, and percutaneous microdiscectomy techniques resulted in rates of $2.1 \%$ (median $2.2 \%$ ), $1.2 \%$ (median $0.8 \%$ ), and $0.5 \%$ (median $0.2 \%$ ), respectively. There was no statically significant difference in reported hematoma or wound complication rates in the meta-analysis.

\section{Recurrent Complications}

Recurrent disc complications were reported by 29 studies and occurred in $4.4 \%$ (median $4.8 \%$ ), $3.1 \%$ (median $3.3 \%$ ), and $3.9 \%$ (median $5.4 \%$ ) of patients undergoing open, MED, and percutaneous microdiscectomy, respectively (Table 4, Figs. 3 and 4). Reoperation occurred at rates of $7.1 \%$ (median 7.1\%), 3.7\% (median 3.3\%), and $10.2 \%$ (median $7.9 \%$ ) for open, MED, and percutaneous techniques, respectively. Meta-analysis calculations indicated no statistically significant difference between the surgical techniques.

\section{Discussion}

This study represents the most comprehensive systematic literature review and meta-analysis of complication rates associated with the various surgical techniques of 


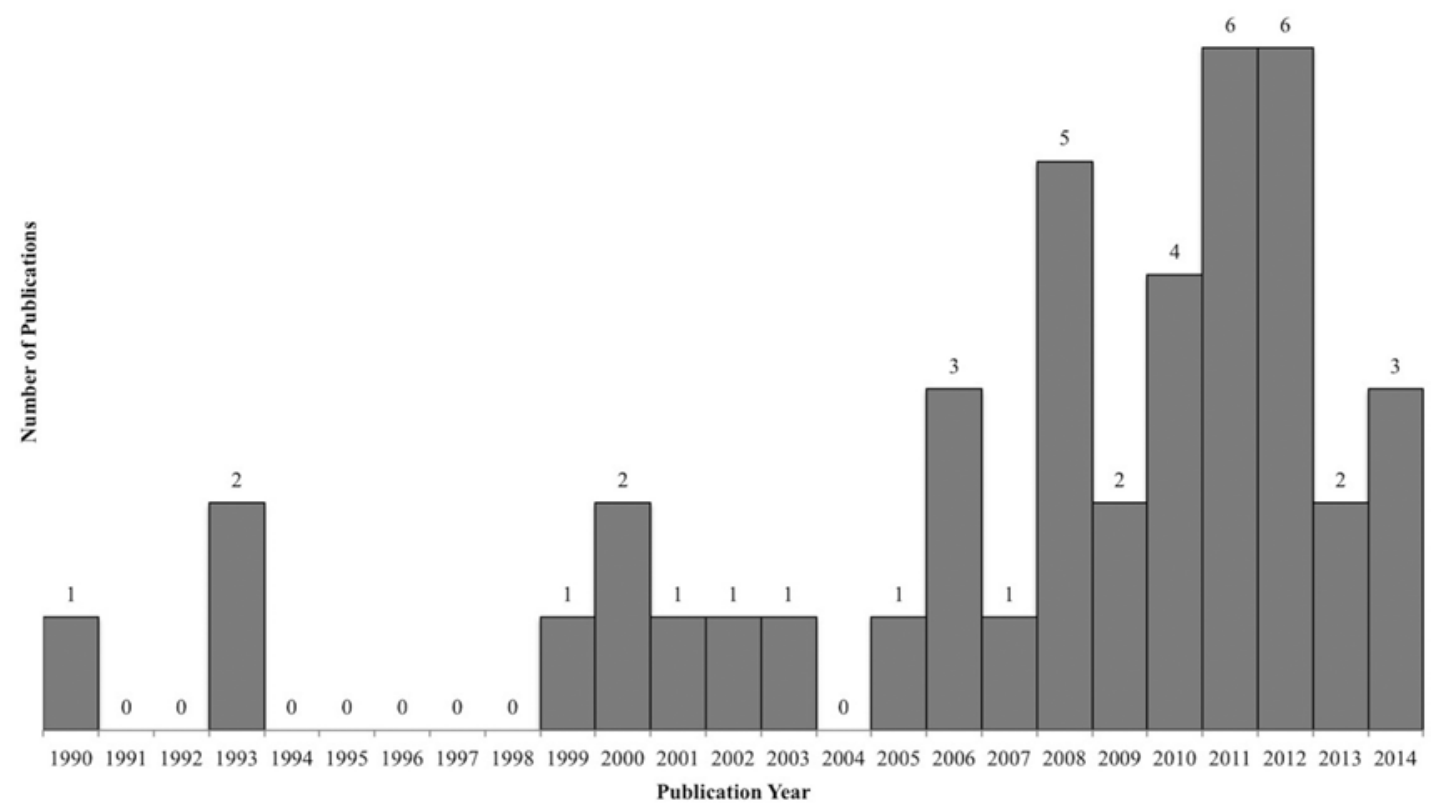

FIG. 2. Included studies according to year of publication.

lumbar microdiscectomy to date. While the 42 included studies represent a small sample of the 2634 total studies screened during our systematic review, we solely evaluated prospective studies because of bias and underreported complication rates outlined in retrospective studies. We analyzed reported complication rates and elucidated differences among open, MED, and percutaneous microdiscectomy procedures.

\section{Open Microdiscectomy and MED}

In our review and meta-analysis, we identified a number of complications following conventional open microdiscectomy and MED. While there were differences in unweighted mean complication rates following both surgical techniques, none reached statistical significance (Fig. 4). The conventional open procedure potentially requires more extensive muscle and soft-tissue dissection, and with its reliance on a microscope, it offers a restricted view during the operation. ${ }^{51} \mathrm{MED}$, on the other hand, achieves resection of the herniated disc by access through a smaller incision and uses a tubular retractor and endoscope. ${ }^{51}$ Prior studies evaluating MED have reported a reduction in postoperative complications. ${ }^{16,35,38,51}$ Authors performing the MED technique have purported better visualization with the endoscope, facilitating enhanced identification and manipulation of anatomical structures such as the nerve root and dural sac., ${ }^{7,51}$ These conclusions suggest that fewer complications should be observed when using MED relative to the conventional open technique. This, however, was not the case in our review. While the MED approach is less invasive for disc resection, we found no significant difference in complication rates compared with open microdiscectomy. We did not evaluate rates of improved neurological outcomes following these procedures because the literature was inconsistent in its reporting.
Garg et al. ${ }^{19}$ have reported that MED results in less paravertebral muscle trauma, fibrosis, and morbidity, along with reduced hospital length of stay, ultimately increasing overall patient satisfaction. Therefore, while MED is indeed associated with a learning curve during initial implementation, the lack of significant differences in complication rates advocates for MED as a potential alternative to traditional open microdiscectomy.

\section{Open Microdiscectomy and Percutaneous Discectomy}

While there were differences in complication rates between open and percutaneous microdiscectomy techniques, none reached statistical significance (Fig. 4). An advantage associated with percutaneous discectomy, over that seen with open conventional discectomy, is the elimination of the need for facet resection because the disc interspace is accessed through the triangle of Kambin, which decreases the risk for spine destabilization. ${ }^{27,48} \mathrm{In}$ addition, a percutaneous approach requires less damage to muscular and ligamentous structures than open microdiscectomy. However, the evaluation of complication rates showed no statistical significance in our meta-analysis. Nonetheless, it is worth noting that there were fewer contributing studies for percutaneous discectomy than for MED and open microdiscectomy. The lack of significant difference in complication rates and advantages in terms of shorter operating time, shorter hospital stay, and disc height preservation suggests that percutaneous discectomy is a potential alternative for minimally invasive surgery. ${ }^{32,47}$ Further prospective or randomized controlled studies are required to more objectively evaluate the outcomes of the 2 techniques.

\section{Limitations}

Most abstracts and studies screened for complication 
TABLE 2. Included studies identified by systematic literature review

\begin{tabular}{|c|c|c|c|c|}
\hline Authors \& Year & Follow-Up (mos) & No. of Patients & Type of Op & Collection Method \\
\hline Galarza et al., 2014 & 24 & 47 & Open & $P$ \\
\hline Hussein et al., 2014 & 96 & Open: 90, MED: 95 & Open, MED & $\mathrm{P}, \mathrm{PR}$ \\
\hline Tsutsumimoto et al., 2014 & 6 & 555 & MED & $\mathrm{P}$ \\
\hline Choi et al., 2013 & 24 & 89 & Percutaneous & $\mathrm{P}, \mathrm{PR}$ \\
\hline Yoshimoto et al., 2013 & 12 & 26 & MED & $\mathrm{P}$, chart \\
\hline Hirano et al., 2012 & 3 & 37 & Percutaneous & $\mathrm{P}$ \\
\hline Kaushal et al., 2012 & 24 & 300 & MED & $P$ \\
\hline Lønne et al., 2012 & 12 & 91 & Open & PR, IO \\
\hline Martín-Láez et al., 2012 & 24 & Open: 101, MED: 37 & Open, MED & $\mathrm{P}$ \\
\hline Righesso et al., 2012 & 24 & 149 & Open & $P$ \\
\hline Wang et al., 2012 & 120 & 151 & MED & $\mathrm{P}, \mathrm{PR}$ \\
\hline Casal-Moro et al., 2011 & 60 & 120 & MED & PR, IO \\
\hline Celik et al., 2011 & 83 & 64 & Open & $\mathrm{P}$, chart \\
\hline Chen et al., 2011 & 12 & 123 & MED & Not defined \\
\hline Choi et al., 2011 & 24 & 52 & Percutaneous & PR \\
\hline Chumnanvej et al., 2011 & 23 & 60 & MED & $P$ \\
\hline Garg et al., 2011 & 12 & Open: 57, MED: 55 & Open, MED & 10 \\
\hline Aronsohn et al., 2010 & 2 & 50 & Percutaneous & Not defined \\
\hline Kaner et al., 2010 & 41 & 40 & Open & Chart \\
\hline Nicassio et al., 2010 & 30 & 262 & Open & Not defined \\
\hline Teli et al., 2010 & 29 & Open: 72, MED: 70 & Open, MED & Chart \\
\hline Arts et al., 2009 & 12 & Open: 159, MED: 166 & Open, MED & 10 \\
\hline Franke et al., 2009 & 12 & 48 & Open & $\mathrm{P}, \mathrm{PR}$ \\
\hline Harrington et al., 2008 & 3 & 35 & Open & Research nurse, chart \\
\hline Parikh et al., 2008 & 9 & 141 & MED & P, PR, chart \\
\hline Peul et al., 2008 & 24 & 180 & Open & Research nurse \\
\hline Ruetten et al., 2008 & 24 & Open: 100, MED: 100 & Open, MED & PR, IO \\
\hline Ryang et al., 2008 & 26 & 30 & Open & PR, IO \\
\hline Righesso et al., 2007 & 24 & 21 & MED & Not defined \\
\hline Ivanic et al., 2006 & 6 & 31 & Open & IO, PR \\
\hline Osterman et al., 2006 & 24 & 28 & Open & PR \\
\hline Tassi, 2006 & 36 & 500 & Open & PR \\
\hline Thomé et al., 2005 & 18 & 42 & Open & PR \\
\hline Türeyen, 2003 & 12 & 63 & Open & PR \\
\hline Aydin et al., 2002 & 32.4 & 200 & Open & PR \\
\hline Huang et al., 2001 & 12 & 11 & MED & Not defined \\
\hline Krugluger et al., 2000 & 24 & 10 & Percutaneous & Not defined \\
\hline Nygaard et al., 2000 & 12 & 39 & Open & 10 \\
\hline Nygaard et al., 1999 & 12 & 98 & Open & 10 \\
\hline Mayer et al., 1993 & 48 & 20 & Percutaneous & 10 \\
\hline Revel et al., 1993 & 6 & 69 & Percutaneous & P, PR \\
\hline Onik et al., 1990 & 12 & 506 & Percutaneous & 10 \\
\hline
\end{tabular}

$\mathrm{IO}=$ independent observer; $\mathrm{P}=$ physician; $\mathrm{PR}=$ patient-reported.

rates in this review were retrospective case series, which limited the number of included studies. As a result, a small number of studies were analyzed, which somewhat restricted our ability to compare surgical techniques. Because of this limitation and concomitant lack of studies with direct comparisons or a consistent control group, we were unable to calculate relative risk values among the procedures. In addition, while stratification of complication rates by age and anatomical levels would decrease heterogeneity and reveal inherent differences associated with these factors, 
TABLE 3. Bias risk assessment for all 42 included studies identified by systematic review

\begin{tabular}{|c|c|c|c|c|c|c|c|}
\hline Authors \& Year & $\begin{array}{l}\text { Study } \\
\text { Type }\end{array}$ & $\begin{array}{l}\text { Sequence } \\
\text { Generation }\end{array}$ & $\begin{array}{c}\text { Allocation } \\
\text { Concealment }\end{array}$ & $\begin{array}{c}\text { Blinding of Participants, } \\
\text { Personnel, \& Outcome } \\
\text { Assessors }\end{array}$ & $\begin{array}{l}\text { Incomplete } \\
\text { Outcome } \\
\text { Data }\end{array}$ & $\begin{array}{l}\text { Select } \\
\text { Outcome } \\
\text { Reporting }\end{array}$ & $\begin{array}{c}\text { Other } \\
\text { Sources of } \\
\text { Bias }\end{array}$ \\
\hline Galarza et al., 2014 & PCS & Low & Unclear & Low & Low & Low & Low \\
\hline Hussein et al., 2014 & RCT & Low & Low & Unclear & Low & Low & Low \\
\hline Tsutsumimoto et al., 2014 & PCS & Low & Unclear & High & Unclear & Low & Low \\
\hline Choi et al., 2013 & PCS & Low & Unclear & Low & Low & Low & Low \\
\hline Yoshimoto et al., 2013 & PCS & Low & Unclear & Low & Low & Low & High \\
\hline Hirano et al., 2012 & PCS & Low & Unclear & Unclear & Low & High & High \\
\hline Kaushal et al., 2012 & PCS & Low & Unclear & Low & Low & Low & High \\
\hline Lønne et al., 2012 & PCS & Low & Unclear & Unclear & Low & High & Low \\
\hline Martín-Láez et al., 2012 & PCS & Low & Low & High & Low & Low & Low \\
\hline Righesso et al., 2012 & PCS & Low & Low & Unclear & Low & Low & Low \\
\hline Wang et al., 2012 & PCS & Low & Unclear & Low & Low & Low & Low \\
\hline Casal-Moro et al., 2011 & PCS & Low & Low & High & Low & Low & High \\
\hline Celik et al., 2011 & RCT & Low & Unclear & Low & Low & Low & Low \\
\hline Chen et al., 2011 & PCS & Unclear & Low & High & Low & Low & Low \\
\hline Choi et al., 2011 & PCS & Low & Unclear & Unclear & Low & Low & Unclear \\
\hline Chumnanvej et al., 2011 & PCS & Low & Unclear & Unclear & Low & Low & Low \\
\hline Garg et al., 2011 & PCS & Low & Low & Low & Low & Low & Low \\
\hline Aronsohn et al., 2010 & RCT & Low & Low & Low & Low & Low & Low \\
\hline Kaner et al., 2010 & PCS & Low & Low & Unclear & Low & Low & Low \\
\hline Nicassio et al., 2010 & PCS & Unclear & High & High & Low & Low & High \\
\hline Teli et al., 2010 & RCT & Low & Low & Low & Low & Low & Low \\
\hline Arts et al., 2009 & RCT & Low & Low & Low & Low & Low & Low \\
\hline Franke et al., 2009 & RCT & Low & Low & Low & Low & Low & Unclear \\
\hline Harrington et al., 2008 & PCS & Unclear & Unclear & Low & Low & Unclear & Low \\
\hline Parikh et al., 2008 & PCS & Unclear & Unclear & Unclear & Low & Low & Unclear \\
\hline Peul et al., 2008 & RCT & Low & Low & Low & Low & Low & Low \\
\hline Ruetten et al., 2008 & RCT & Low & Low & Low & Low & Low & Low \\
\hline Ryang et al., 2008 & RCT & Low & Low & Low & Low & Low & Low \\
\hline Righesso et al., 2007 & RCT & Low & Low & Low & Low & Low & Low \\
\hline Ivanic et al., 2006 & RCT & Low & Unclear & Low & Low & Low & Low \\
\hline Osterman et al., 2006 & RCT & Low & Unclear & Low & Low & Low & Low \\
\hline Tassi, 2006 & PCS & Low & Unclear & High & Low & Low & Low \\
\hline Thomé et al., 2005 & PCS & Low & Low & Unclear & Low & Low & Low \\
\hline Türeyen, 2003 & PCS & Low & Unclear & Unclear & Low & Low & Low \\
\hline Aydin et al., 2002 & PCS & Low & Low & Low & Low & Low & Low \\
\hline Huang et al., 2001 & PCS & Low & Unclear & Low & Low & Low & Low \\
\hline Krugluger et al., 2000 & RCT & Low & Unclear & Unclear & Low & Low & Unclear \\
\hline Nygaard et al., 2000 & PCS & Low & Unclear & High & Low & Low & Low \\
\hline Nygaard et al., 1999 & PCS & Low & High & Low & Low & Low & Low \\
\hline Mayer et al., 1993 & RCT & Low & Low & Low & Low & Low & Low \\
\hline Revel et al., 1993 & RCT & Low & Low & Low & Low & Low & Low \\
\hline Onik et al., 1990 & PCS & Low & Low & Unclear & Unclear & Low & Low \\
\hline
\end{tabular}


TABLE 4. Complication rates for open, MED, and percutaneous microdiscectomy

\begin{tabular}{|c|c|c|c|c|}
\hline Neurological Injuries & Contributing Studies & No. of Patients & Overall Rate* & Interstudy Median Rate (IQR)† \\
\hline \multicolumn{5}{|l|}{ Nerve root injury } \\
\hline Open & 7 & 618 & $2.6 \%$ & $0.0 \%(0.0 \%-0.9 \%)$ \\
\hline MED & 10 & 1065 & $0.9 \%$ & $0.7 \%(0.0 \%-1.6 \%)$ \\
\hline Percutaneous & 2 & 89 & $1.1 \%$ & $0.7 \%(0.4 \%-1.1 \%)$ \\
\hline \multicolumn{5}{|c|}{ New or worsening neurological deficit } \\
\hline Open & 6 & 1069 & $1.3 \%$ & $1.2 \%(0.5 \%-1.7 \%)$ \\
\hline MED & 7 & 573 & $3.0 \%$ & $2.8 \%(0.0 \%-3.1 \%)$ \\
\hline Percutaneous & 2 & 62 & $1.6 \%$ & $5.0 \%(2.5 \%-7.5 \%)$ \\
\hline \multicolumn{5}{|l|}{ General complications } \\
\hline \multicolumn{5}{|l|}{ Medical complications } \\
\hline Open & 5 & 384 & $2.6 \%$ & $2.6 \%(2.5 \%-3.6 \%)$ \\
\hline MED & 5 & 587 & $2.6 \%$ & $0.0 \%(0.0 \%-0.8 \%)$ \\
\hline Percutaneous & - & - & - & - \\
\hline \multicolumn{5}{|l|}{ Surgical errors } \\
\hline Open & 1 & 159 & $3.1 \%$ & $3.1 \%$ \\
\hline MED & 2 & 286 & $1.0 \%$ & $1.0 \%(0.9 \%-1.1 \%)$ \\
\hline Percutaneous & - & - & - & - \\
\hline \multicolumn{5}{|l|}{ Durotomy complications } \\
\hline \multicolumn{5}{|l|}{ Durotomy } \\
\hline Open & 14 & 1479 & $3.9 \%$ & $4.9 \%(1.5 \%-6.0 \%)$ \\
\hline MED & 15 & 2019 & $4.5 \%$ & $4.8 \%(1.2 \%-7.4 \%)$ \\
\hline Percutaneous & - & - & - & - \\
\hline \multicolumn{5}{|l|}{ Wound complications } \\
\hline \multicolumn{5}{|l|}{ Hematoma } \\
\hline Open & 4 & 930 & $0.5 \%$ & $0.6 \%(0.5 \%-0.7 \%)$ \\
\hline MED & 1 & 166 & $1.2 \%$ & $1.2 \%$ \\
\hline Percutaneous & 4 & 716 & $0.6 \%$ & $0.8 \%(0.1 \%-1.6 \%)$ \\
\hline \multicolumn{5}{|l|}{ Wound complications } \\
\hline Open & 16 & 2016 & $2.1 \%$ & $2.2 \%(0.9 \%-3.4 \%)$ \\
\hline MED & 13 & 1378 & $1.2 \%$ & $0.8 \%(0.0 \%-2.0 \%)$ \\
\hline Percutaneous & 4 & 628 & $0.5 \%$ & $0.2 \%(0.0 \%-0.8 \%)$ \\
\hline \multicolumn{5}{|l|}{ Recurrent complications } \\
\hline \multicolumn{5}{|l|}{ Recurrent disc complications } \\
\hline Open & 14 & 1192 & $4.4 \%$ & $4.8 \%(2.7 \%-6.1 \%)$ \\
\hline MED & 12 & 1599 & $3.1 \%$ & $3.3 \%(1.8 \%-5.1 \%)$ \\
\hline Percutaneous & 3 & 178 & $3.9 \%$ & $5.4 \%(3.8 \%-5.6 \%)$ \\
\hline \multicolumn{5}{|l|}{ Reoperation } \\
\hline Open & 16 & 1631 & $7.1 \%$ & $7.1 \%(4.8 \%-10.1 \%)$ \\
\hline MED & 14 & 1719 & $3.7 \%$ & $3.3 \%(2.1 \%-6.2 \%)$ \\
\hline Percutaneous & 6 & 714 & $10.2 \%$ & $7.9 \%(5.5 \%-11.4 \%)$ \\
\hline
\end{tabular}

the primary literature is varied and does not routinely discuss these factors in reporting complications. Finally, this meta-analysis solely investigated complications associated with single-level lumbar microdiscectomy. Further research should be performed to explore complication rates across all forms of lumbar surgery, allowing for comparative effectiveness investigation.

\section{Conclusions}

This work presents a systematic review of complications reported in 42 studies published between 1990 and 2014, comparing the differences in complication rates among open microdiscectomy, MED, and percutaneous discectomy. Previous clinical studies have purported reduced complications when utilizing MIS techniques, but our analysis of complication rates following open microdiscectomy and MED showed no statistically significant differences. Furthermore, differences in complication rates between open microdiscectomy and percutaneous discectomy were not statistically significant. The resultant list of complications should serve as a framework to provide an educated and reasonably comprehensive informed consent discussion 


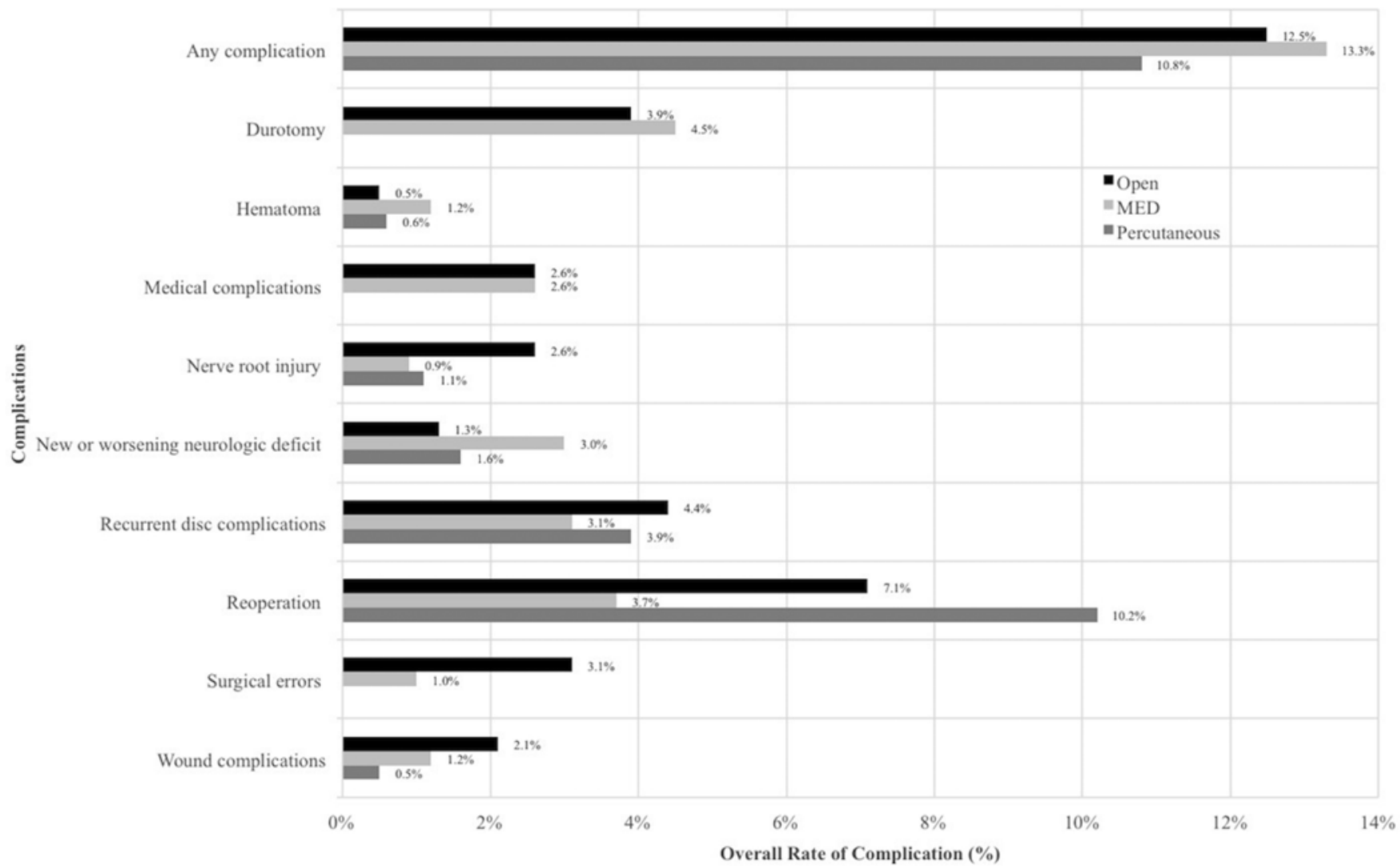

FIG. 3. Combined bar graph for the overall rates of various complications across open, microendoscopic, and percutaneous lumbar microdiscectomy.

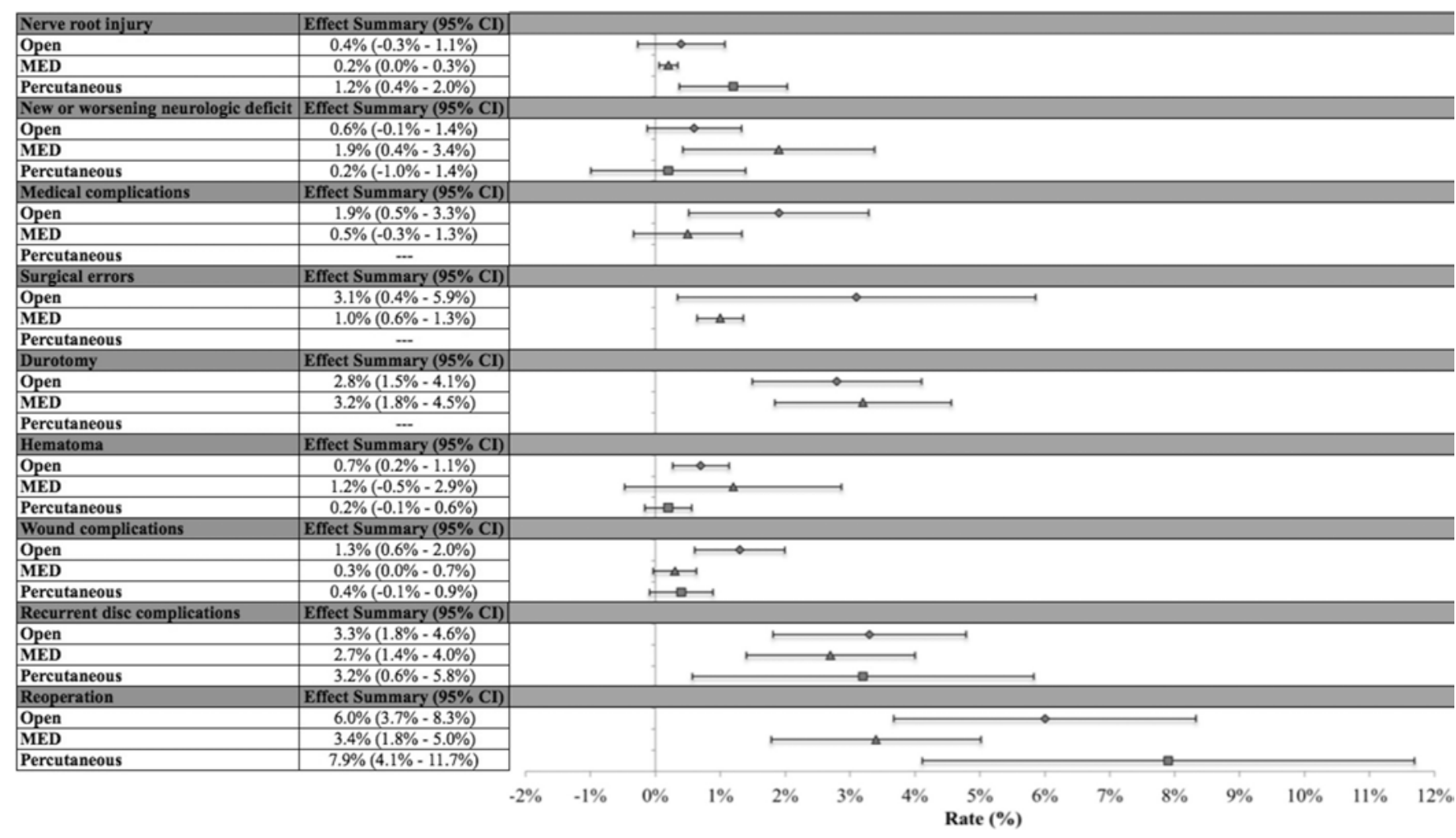

FIG. 4. Meta-analysis effect summary values and $95 \% \mathrm{Cls}$ for identified complications following each surgical technique. 
between the surgeon and the patient regarding potential expectations as well as alternative surgical techniques.

\section{References}

1. Aronsohn J, Chapman K, Soliman M, Shah T, Costandi S, Michael R, et al: Percutaneous microdiscectomy versus epidural injection for management of chronic spinal pain. Proc West Pharmacol Soc 53:16-19, 2010

2. Arts MP, Brand R, van den Akker ME, Koes BW, Bartels RH, Peul WC: Tubular diskectomy vs conventional microdiskectomy for sciatica: a randomized controlled trial. JAMA 302:149-158, 2009

3. Aydin Y, Ziyal IM, Duman H, Türkmen CS, Başak M, Sahin Y: Clinical and radiological results of lumbar microdiskectomy technique with preserving of ligamentum flavum comparing to the standard microdiskectomy technique. Surg Neurol 57:5-14, 2002

4. Cahill KS, Dunn I, Gunnarsson T, Proctor MR: Lumbar microdiscectomy in pediatric patients: a large single-institution series. J Neurosurg Spine 12:165-170, 2010

5. Cahill KS, Levi AD, Cummock MD, Liao W, Wang MY: A comparison of acute hospital charges after tubular versus open microdiskectomy. World Neurosurg 80:208-212, 2013

6. Casal-Moro R, Castro-Menéndez M, Hernández-Blanco M, Bravo-Ricoy JA, Jorge-Barreiro FJ: Long-term outcome after microendoscopic diskectomy for lumbar disk herniation: a prospective clinical study with a 5-year follow-up. Neurosurgery 68:1568-1575, 2011

7. Caspar W: A new surgical procedure for lumbar disc herniation causing less tissue damage through a microsurgical approach. Adv Neurosurg 4:74-80, 1977

8. Caspar W, Campbell B, Barbier DD, Kretschmmer R, Gotfried Y: The Caspar microsurgical discectomy and comparison with a conventional standard lumbar disc procedure. Neurosurgery 28:78-87, 1991

9. Çelik S, Göksu K, Çelik SE, Emir CB: Benign neurological recovery with low recurrence and low peridural fibrosis rate in pediatric disc herniations after lumbar microdiscectomy. Pediatr Neurosurg 47:417-422, 2011

10. Chen HT, Tsai CH, Chao SC, Kao TH, Chen YJ, Hsu HC, et al: Endoscopic discectomy of L5-S1 disc herniation via an interlaminar approach: Prospective controlled study under local and general anesthesia. Surg Neurol Int 2:93, 2011

11. Choi G, Modi HN, Prada N, Ahn TJ, Myung SH, Gang MS, et al: Clinical results of XMR-assisted percutaneous transforaminal endoscopic lumbar discectomy. J Orthop Surg 8:14, 2013

12. Choi KC, Kim JS, Kang BU, Lee CD, Lee SH: Changes in back pain after percutaneous endoscopic lumbar discectomy and annuloplasty for lumbar disc herniation: a prospective study. Pain Med 12:1615-1621, 2011

13. Chumnanvej S, Kesornsak W, Sarnvivad P, Paiboonsirijit S, Kuansongthum V: Full endoscopic lumbar discectomy via interlaminar approach: 2-year results in Ramathibodi Hospital. J Med Assoc Thai 94:1465-1470, 2011 (Erratum in J Med Assoc Thai 95:296, 2011)

14. DeLong WB, Polissar N, Neradilek B: Timing of surgery in cauda equina syndrome with urinary retention: meta-analysis of observational studies. J Neurosurg Spine 8:305-320, 2008

15. Fessler RG, O'Toole JE, Eichholz KM, Perez-Cruet MJ: The development of minimally invasive spine surgery. Neurosurg Clin N Am 17:401-409, 2006

16. Foley KT, Smith MM: Microendoscopic discectomy. Tech Neurosurg 3:301-307, 1997

17. Franke J, Greiner-Perth R, Boehm H, Mahlfeld K, Grasshoff $\mathrm{H}$, Allam Y, et al: Comparison of a minimally invasive procedure versus standard microscopic discotomy: a prospective randomised controlled clinical trial. Eur Spine J 18:9921000,2009

18. Galarza M, Gazzeri R, De la Rosa P, Martínez-Lage JF: Microdiscectomy with and without insertion of interspinous device for herniated disc at the L5-S1 level. J Clin Neurosci 21:1934-1939, 2014

19. Garg B, Nagraja UB, Jayaswal A: Microendoscopic versus open discectomy for lumbar disc herniation: a prospective randomised study. J Orthop Surg (Hong Kong) 19:30-34, 2011

20. Guyer RD, Foley KT, Phillips FM, Ball PA: Minimally invasive fusion: summary statement. Spine (Phila Pa 1976) 28 (15 Suppl):S44, 2003

21. Harrington JF, French P: Open versus minimally invasive lumbar microdiscectomy: comparison of operative times, length of hospital stay, narcotic use and complications. Minim Invasive Neurosurg 51:30-35, 2008

22. Higgins JPT, Green S (eds): Cochrane Handbook for Systematic Reviews of Interventions, Version 5.1.0. London: The Cochrane Collaboration, 2011 (http://handbook. cochrane.org) [Accessed August 5, 2015]

23. Hirano Y, Mizuno J, Takeda M, Itoh Y, Matsuoka H, Watanabe K: Percutaneous endoscopic lumbar discectomy - early clinical experience. Neurol Med Chir (Tokyo) 52:625-630, 2012

24. Huang TJ, Hsu RW, Lee YY, Chen SH: Video-assisted endoscopic lumbar discectomy. Surg Endosc 15:1175-1178, 2001

25. Hussein M, Abdeldayem A, Mattar MM: Surgical technique and effectiveness of microendoscopic discectomy for large uncontained lumbar disc herniations: a prospective, randomized, controlled study with 8 years of follow-up. Eur Spine J 23:1992-1999, 2014

26. Ivanic GM, Pink PT, Schneider F, Stuecker M, Homann NC, Preidler KW: Prevention of epidural scarring after microdiscectomy: a randomized clinical trial comparing gel and expanded polytetrafluoroethylene membrane. Eur Spine J 15:1360-1366, 2006

27. Kambin P, Brager MD: Percutaneous posterolateral discectomy. Anatomy and mechanism. Clin Orthop Relat Res (223):145-154, 1987

28. Kaner T, Sasani M, Oktenoglu T, Aydin AL, Ozer AF: Minimum two-year follow-up of cases with recurrent disc herniation treated with microdiscectomy and posterior dynamic transpedicular stabilisation. Open Orthop J 4:120-125, 2010

29. Kaushal M, Sen R: Posterior endoscopic discectomy: Results in 300 patients. Indian J Orthop 46:81-85, 2012

30. Krugluger J, Knahr K: Chemonucleolysis and automated percutaneous discectomy-a prospective randomized comparison. Int Or thop 24:167-169, 2000

31. Lau D, Han SJ, Lee JG, Lu DC, Chou D: Minimally invasive compared to open microdiscectomy for lumbar disc herniation. J Clin Neurosci 18:81-84, 2011

32. Lee DY, Shim CS, Ahn Y, Choi YG, Kim HJ, Lee SH: Comparison of percutaneous endoscopic lumbar discectomy and open lumbar microdiscectomy for recurrent disc herniation. J Korean Neurosurg Soc 46:515-521, 2009

33. Lønne G, Solberg TK, Sjaavik K, Nygaard OP: Recovery of muscle strength after microdiscectomy for lumbar disc herniation: a prospective cohort study with 1-year follow-up. Eur Spine J 21:655-659, 2012

34. Lubelski D, Mihalovich KE, Skelly AC, Fehlings MG, Harrop JS, Mummaneni PV, et al: Is minimal access spine surgery more cost-effective than conventional spine surgery? Spine (Phila Pa 1976) 39 (22 Suppl 1):S65-S74, 2014

35. Maroon JC: Current concepts in minimally invasive discectomy. Neurosurgery 51 (5 Suppl):S137-S145, 2002

36. Martín-Láez R, Martínez-Agüeros JA, Suárez-Fernández D, Montiaga-Núñez F, Vázquez-Barquero A: Complications of endoscopic microdiscectomy using the EASYGO! system: is there any difference with conventional discectomy during the 
learning-curve period? Acta Neurochir (Wien) 154:10231032,2012

37. Mayer HM, Brock M: Percutaneous endoscopic discectomy: surgical technique and preliminary results compared to microsurgical discectomy. J Neurosurg 78:216-225, 1993

38. Mixter WJ, Barr JS: Rupture of the intervertebral disc with involvement of the spinal canal. N Engl J Med 211:210-215, 1934

39. Moher D, Liberati A, Tetzlaff J, Altman DG: Preferred reporting items for systematic reviews and meta-analyses: the PRISMA statement. BMJ 339:b2535, 2009

40. Neyeloff JL, Fuchs SC, Moreira LB: Meta-analyses and Forest plots using a Microsoft Excel spreadsheet: step-by-step guide focusing on descriptive data analysis. BMC Res Notes $\mathbf{5 : 5 2 , 2 0 1 2}$

41. Nicassio N, Bobicchio P, Umari M, Tacconi L: Lumbar microdiscectomy under epidural anaesthesia with the patient in the sitting position: a prospective study. J Clin Neurosci 17:1537-1540, 2010

42. Nygaard OP, Jacobsen EA, Solberg T, Kloster R, Dullerud R: Postoperative nerve root displacement and scar tissue. A prospective cohort study with contrast-enhanced MR imaging one year after microdiscectomy. Acta Radiol 40:598-602, 1999

43. Nygaard OP, Kloster R, Solberg T, Mellgren SI: Recovery of function in adjacent nerve roots after surgery for lumbar disc herniation: use of quantitative sensory testing in the exploration of different populations of nerve fibers. J Spinal Disord 13:427-431, 2000

44. Onik G, Mooney V, Maroon JC, Wiltse L, Helms C, Schweigel J, et al: Automated percutaneous discectomy: a prospective multi-institutional study. Neurosurgery 26:228-233, 1990

45. Osterman H, Seitsalo S, Karppinen J, Malmivaara A: Effectiveness of microdiscectomy for lumbar disc herniation: a randomized controlled trial with 2 years of follow-up. Spine (Phila Pa 1976) 31:2409-2414, 2006

46. Parikh K, Tomasino A, Knopman J, Boockvar J, Härtl R: Operative results and learning curve: microscope-assisted tubular microsurgery for 1- and 2-level discectomies and laminectomies. Neurosurg Focus 25(2):E14, 2008

47. Peng CW, Yeo W, Tan SB: Percutaneous endoscopic discectomy: clinical results and how it affects the quality of life. $\mathbf{J}$ Spinal Disord Tech 23:425-430, 2010

48. Peng CW, Yeo W, Tan SB: Percutaneous endoscopic lumbar discectomy: clinical and quality of life outcomes with a minimum 2 year follow-up. J Orthop Surg 4:20, 2009

49. Peul WC, van den Hout WB, Brand R, Thomeer RT, Koes BW: Prolonged conservative care versus early surgery in patients with sciatica caused by lumbar disc herniation: two year results of a randomised controlled trial. BMJ 336:13551358,2008

50. Revel M, Payan C, Vallee C, Laredo JD, Lassale B, Roux C, et al: Automated percutaneous lumbar discectomy versus chemonucleolysis in the treatment of sciatica. A randomized multicenter trial. Spine (Phila Pa 1976) 18:1-7, 1993

51. Righesso O, Falavigna A, Avanzi O: Comparison of open discectomy with microendoscopic discectomy in lumbar disc herniations: results of a randomized controlled trial. Neurosurgery 61:545-549, 2007

52. Righesso O, Falavigna A, Avanzi O: Correlation between persistent neurological impairment and clinical outcome after microdiscectomy for treatment of lumbar disc herniation. Neurosurgery 70:390-397, 2012

53. Ruetten S, Komp M, Merk H, Godolias G: Full-endoscopic interlaminar and transforaminal lumbar discectomy versus conventional microsurgical technique: a prospective, randomized, controlled study. Spine (Phila Pa 1976) 33:931939, 2008
54. Ryang YM, Oertel MF, Mayfrank L, Gilsbach JM, Rohde V: Standard open microdiscectomy versus minimal access trocar microdiscectomy: results of a prospective randomized study. Neurosurgery 62:174-182, 2008

55. Sihvonen T, Herno A, Paljärvi L, Airaksinen O, Partanen J, Tapaninaho A: Local denervation atrophy of paraspinal muscles in postoperative failed back syndrome. Spine (Phila Pa 1976) 18:575-581, 1993

56. Tassi GP: Comparison of results of 500 microdiscectomies and 500 percutaneous laser disc decompression procedures for lumbar disc herniation. Photomed Laser Surg 24:694697,2006

57. Teli M, Lovi A, Brayda-Bruno M, Zagra A, Corriero A, Giudici F, et al: Higher risk of dural tears and recurrent herniation with lumbar micro-endoscopic discectomy. Eur Spine J 19:443-450, 2010

58. Thomé C, Barth M, Scharf J, Schmiedek P: Outcome after lumbar sequestrectomy compared with microdiscectomy: a prospective randomized study. J Neurosurg Spine 2:271278,2005

59. Thongtrangan I, Le H, Park J, Kim DH: Minimally invasive spinal surgery: a historical perspective. Neurosurg Focus 16(1):E13, 2004

60. Tsutsumimoto T, Yui M, Uehara M, Ohta H, Kosaku H, Misawa $\mathrm{H}$ : A prospective study of the incidence and outcomes of incidental dural tears in microendoscopic lumbar decompressive surgery. Bone Joint J 96-B:641-645, 2014

61. Türeyen K: One-level one-sided lumbar disc surgery with and without microscopic assistance: 1-year outcome in 114 consecutive patients. J Neurosurg 99 (3 Suppl):247-250, 2003

62. Wang M, Zhou Y, Wang J, Zhang Z, Li C: A 10-year followup study on long-term clinical outcomes of lumbar microendoscopic discectomy. J Neurol Surg A Cent Eur Neurosurg 73:195-198, 2012

63. Weinstein JN, Lurie JD, Tosteson TD, Tosteson AN, Blood EA, Abdu WA, et al: Surgical versus nonoperative treatment for lumbar disc herniation: four-year results for the Spine Patient Outcomes Research Trial (SPORT). Spine (Phila Pa 1976) 33:2789-2800, 2008

64. Yoshimoto M, Takebayashi T, Ida K, Tanimoto K, Yamashita T: Microendoscopic discectomy in athletes. J Orthop Sci 18:902-908, 2013

\section{Disclosure}

Dr. Benzel has an ownership interest (stock options) in Axiomed, DePuy, Orthomens, and Turning Point. He also has grants from OREF and Rawlings. He receives royalties from Elsevier and Thieme as well. Dr. Mroz has received personal fees from Globus, AOSpine, and CeramTec and has an ownership interest (stock options) in PearlDriver, Inc. He has also received faculty honoraria from AOSpine.

\section{Author Contributions}

Conception and design: Shriver, Xie, Rosenbaum, Kshettry. Acquisition of data: Shriver, Xie, Tye. Analysis and interpretation of data: Shriver, Xie, Tye. Drafting the article: Shriver, Xie, Critically revising the article: Shriver, Xie, Rosenbaum, Kshettry, Benzel, Mroz. Reviewed submitted version of manuscript: all authors. Approved the final version of the manuscript on behalf of all authors: Shriver. Statistical analysis: Xie, Tye.

\section{Correspondence}

Michael F. Shriver, Case Western Reserve University School of Medicine, 2109 Adelbert Rd., Cleveland, OH 44106. email: mfs82@case.edu. 